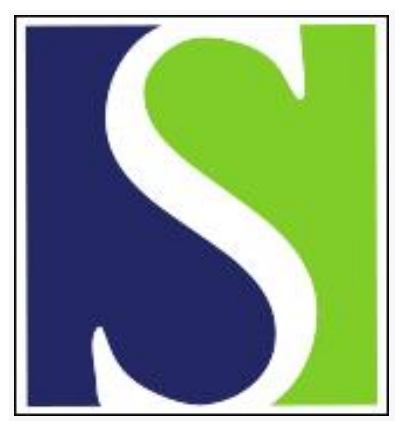

Scand J Work Environ Health 2011;37(1):70-76

https://doi.org/10.5271/sjweh.2916

Published online: 06 Apr 2010, Issue date: Jan 2011

The effectiveness of yoga for the improvement of well-being and resilience to stress in the workplace

by Hartfiel N, Havenhand J, Khalsa SB, Clarke G, Krayer A

Affiliation: Dru Education Centre, Snowdonia Mountain Lodge, Bethesda LL57 3LX, United Kingdom. ned@druworldwide.com

The following articles refer to this text: 2011;37(1):80;

2019;45(6):533-545

Key terms: breathing exercise; effectiveness; health; health; improvement; movement; occupational health; physical activity; positive health; randomized controlled trial; RCT; relaxation; resilience; stress; well-being; workplace; yoga

This article in PubMed: www.ncbi.nlm.nih.gov/pubmed/20369218 


\title{
The effectiveness of yoga for the improvement of well-being and resilience to stress in the workplace
}

\author{
by Ned Hartfiel, MSc, ${ }^{1}$ Jon Havenhand, PhD, ${ }^{2}$ Sat Bir Khalsa, PhD, ${ }^{3}$ Graham Clarke, PhD, ${ }^{4}$ \\ Anne Krayer, $P h D^{5}$
}

\begin{abstract}
Hartfiel N, Havenhand J, Khalsa SB, Clarke G, Krayer A. The effectiveness of yoga for the improvement of well-being and resilience to stress in the workplace. Scand J Work Environ Health. 2011;37(1):70-76.
\end{abstract}

Objectives Recent research has indicated concern for the degree of stress and emotional well-being among university staff. This study examined the effectiveness of yoga in enhancing emotional well-being and resilience to stress among university employees.

Methods In a randomized controlled trial at a British university, we recruited 48 employees and randomized them into either a yoga or a wait-list control group. The yoga group was offered six weeks of Dru Yoga, comprising one 60-minute class per week. These classes were offered by a certified Dru Yoga instructor at lunchtime from January-March 2008. The wait-list control group received no intervention during this six-week study. Baseline and end-program measurements of self-reported mood and well-being were self-assessed with the Profile of Mood States - Bipolar (POMS-Bi) and the Inventory of Positive Psychological Attitudes (IPPA).

Results This six-week yoga intervention resulted in significantly improved POMS-Bi and IPPA scores for the yoga compared to the wait-list control group for seven of eight measures of mood and well-being. In comparison to the wait-list control group at baseline and the end of the program, the yoga group reported marked improvements in feelings of clear-mindedness, composure, elation, energy, and confidence. In addition, the yoga group reported increased life purpose and satisfaction, and feelings of greater self-confidence during stressful situations.

Conclusion These results show that even a short program of yoga is effective for enhancing emotional wellbeing and resilience to stress in the workplace. We suggest that employers should consider offering yoga classes to their employees.

Key terms breathing exercise; movement; occupational health; physical activity; positive health; randomized controlled trial; RCT; relaxation.

Improving well-being and resilience to stress are key issues facing many organizations (1-2). In the UK alone, $97 \%$ of senior human resources professionals believe stress is the biggest threat to the future health of the workforce (3), and estimates suggest 175 million working days are lost each year in the UK due to sickness absence, half of which are stress-related (4). There is also a growing trend toward long-term absences of $\geq 20$ days, due in large part to psychosocial factors such as stress, anxiety, and depression (5).
Well-being in the workplace is characterized by employees who perceive themselves to be growing, engaged, and productive and who experience positive emotional states such as pleasure, joy, and energy that help buffer against stress and depression (6-8). Stress has been defined as the inability to cope with a perceived threat to one's mental, physical, emotional, and spiritual well-being (9). Resilience to stress means that employees can respond productively when faced with significant change or pressure to achieve outcomes (10).

\footnotetext{
1 Dru Education Centre, Snowdonia Mountain Lodge, Bethesda LL57 3LX, United Kingdom.

2 University of Gothenburg, Department of Marine Ecology - Tjärnö, Strömstad 45296, Sweden.

3 Harvard Medical School, Department of Medicine, Brigham and Women's Hospital, Boston, MA 02115-5817, United States.

4 Bangor University, School of Healthcare Sciences, Bangor LL57 2EF, United Kingdom.

5 Bangor University, Centre for Applied Research and Evaluation in Social Care, Bangor LL57 2DG, United Kingdom.
}

Correspondence to: Ned Hartfiel, Dru Education Centre, Snowdonia Mountain Lodge, Bethesda LL57 3LX, United Kingdom. [E-mail: ned@druworldwide.com] 
Although pressure to achieve outcomes is expected in the workplace, excessive pressure can undermine both physical health and psychological well-being. Among university employees, increases in workloads and studentto-staff ratios have led to a significant increase in occupational stress, anxiety, and depression (11-14). Research indicates strong links between stress and such conditions as anxiety and depression, heart disease, back pain, headaches, and gastrointestinal disturbances (15-19).

In 2008, the National Institute for Health and Clinical Excellence (NICE) estimated that losses arising from a lack of physical activity among workers were costing UK companies $£ 8.2$ billion per year (20). Consequently, NICE has called for an increase in the levels of physical activity at work to improve well-being in the workplace. Recent evidence (21) has shown that workplace programs of physical activity [ie, "bodily movement produced by skeletal muscles resulting in energy expenditure" (22)] have a positive effect on employees. This positive effect extends to workplace activity programs that include yoga, an ancient form of health promotion involving physical activity, breathing exercises, and relaxation (23-26).

Participation in yoga has increased significantly in the past two decades. In 2003, the British Broadcasting Corporation (BBC) reported that yoga had "joined the mainstream" (27). Although we are not aware of any reliable yoga statistics in the UK, nationwide surveys in the United States have indicated that the number of people practicing yoga has more than doubled, from approximately 7 million people in 1998 to $>15$ million in 2008 (28-30). By 2008, approximately $5 \%$ of US businesses, including many Fortune 500 companies, were offering yoga at the workplace (31-33).

Posadzki \& Parekh (34) recently reviewed the physical and psychological benefits of yoga. These include increased cardiopulmonary and central nervous system (CNS) function and reduced respiration rate, blood pressure, fatigue, and symptoms of anxiety and depression (34-35). Long-term yoga practice ( $2-5$ years) has been shown to reduce perceived stress (36) and increase self-assessed well-being, however mechanistic links to reductions in physiological stress remain unclear (37). In view of this growing evidence, it is not surprising that recent research has suggested that yoga may be effective for improving well-being in the workplace (24-26).

In a review of several preliminary workplace yoga studies, Gura (25) reported on the effectiveness of yoga for the improvement of well-being and reduction of absenteeism in the workplace. Granath et al (24) investigated the effects of yoga and cognitive behavior therapy in a large Swedish company and found that both yoga and the therapy were successful in enhancing quality of life. Both Gura (25) and Granath et al (24) called for randomized controlled trials to more rigorously assess the potential benefits of workplace yoga. As far as we are aware, the study described here is the first randomized controlled trial that tests the hypothesis that yoga is effective for enhancing emotional well-being and resilience to stress in the workplace.

\section{Methods}

Conducted at a British university, this study used a randomized wait-list control design and received institutional ethical approval in November 2007. In December 2007 and January 2008, a sample of 48 university employees were self-selected from the university intranet and via flyers posted throughout the university. Participants were then e-mailed a "participant information sheet" and a "health information form". The former explained the purpose of the study (ie, to determine the effectiveness of yoga for reducing psychological stress and enhancing emotional well-being), and the latter asked participants to identify any health concerns from a list of 24 common conditions (eg, arthritis, asthma, depression, heart conditions, being overweight, etc).

Completed health information forms were assessed by a senior Dru Yoga instructor to ensure safe-practice and good health status. Dru Yoga was the chosen intervention because it is a particularly safe, accessible, and therapeutic form of yoga that can be practiced by most people (38). Participants with "at risk" health conditions (eg, recent surgery, first trimester pregnancy) would have been excluded from this study, but no participants met these criteria. The health information form also asked participants to indicate how often they currently practiced yoga. Participants practicing yoga once per week or more $(\mathrm{N}=2)$ were excluded from the analysis of this study, although they were allowed to participate in the classes.

In January 2008, participants in this study were then randomized (using www.randomizer.org) into a yoga intervention and a wait-list control group. Group membership was "non-blinded". After randomization, outcome variables were measured at the beginning (baseline) and end of the program (six weeks later). The wait-list control group received neither intervention, instructions nor restrictions on their activity during the six-week study period. Upon completion of the study, this group received a six-week yoga intervention in April and May 2008. All classes were free of charge to the participants.

\section{Yoga intervention}

The 24 participants in the yoga intervention group were asked to attend at least one of three 60-minute lunchtime classes per week for six weeks taught by a senior Dru Yoga instructor. Each participant in the 
yoga intervention also received a Dru Yoga $\mathrm{CD}$, which included a guided 35-minute home practice session, and a home practice form to record the frequency and duration of their sessions at home.

The Dru Yoga classes consisted of flowing movements, directed breathing, and relaxation techniques that included affirmation and visualization (39). Each class was divided into four stages: activation exercises, energy-block release sequences, postures, and relaxation (table 1).

\section{Outcome measures}

The outcome measures selected to measure well-being and resilience to stress were the Profile of Mood States Bipolar (POMS-Bi) (40) and the Inventory of Positive Psychological Attitudes (IPPA) (41). Most assessment tools in clinical settings measure only negative moods, which are considered more appropriate for participants with mental/emotional problems [eg, Perceived Stress Scale (PSS), or State Trait Anxiety Inventory (STAI) (40-41)]. However, the POMS-Bi and IPPA assess both positive and negative emotional states and are, therefore, considered appropriate for "normal" respondents such as the university staff surveyed in this study (40-41). Both the POMS-Bi and IPPA have been used or recommended as metrics for measuring psychological stress (42-45), and they have demonstrated a strong degree of concurrent validity and internal reliability (40-41).

The POMS-Bi is a 72 -item adjective checklist assessing six domains of emotional well-being: (i) composed-anxious, (ii) clear-minded-confused, (iii) elated-depressed, (iv) energized-tired, (v) agreeablehostile, and (vi) confident-unsure. Respondents indicate how many of the 72 adjectives describe how they have been feeling during the past week. The checklist takes approximately 10 minutes to complete and uses a 4point Likert scale ranging from 1 ("much unlike this") to 4 ("much like this").

The IPPA questionnaire measures two additional states of emotional well-being: (i) life purpose and satisfaction and (ii) self-confidence during stressful situations. The IPPA takes approximately 10 minutes to complete and contains 32 statements; 17 statements are allocated to measuring "life purpose and satisfaction" and 15 to "self-confidence during stressful situations". The IPPA uses a 7-point Likert scale, whereby respondents indicate how much each statement is true for them at the time of completing the questionnaire (table 2). Participant responses to each statement can range from 1 ("very low agreement") to 7 ("very high agreement").

\section{Statistical analysis}

Statistical analysis was performed using the Statistical Package in the Social Sciences version 14.2 (SPSS Inc, Chicago, IL, USA). Prior to analysis, all data were checked for homogeneity of variances and normality using Q-Q plots and box plots (46). Baseline and end-program data were compared using a two-way ANOVA on all six domains of the POMS-Bi and the two domains of the IPPA. The significance of the interaction term from these analyses (table 3 ) was assessed using a sequential Bonferroni correction on the entire set of domains (47). SPSS 14.2 used pairwise deletion to treat the very small number of missing values ( $0.1 \%$ of all responses) from the POMS-Bi and IPPA questionnaires (48).

Table 1. Dru Yoga Intervention. Details of Dru Yoga movements and postures can be found in Barrington et al (39).

\begin{tabular}{ll}
\hline Stage & Description \\
\hline Activation exercises (10 minutes) & $\begin{array}{l}\text { Flowing warm-up movements aimed at enhancing circulation, releasing tension, and preparing the } \\
\text { body for movement. }\end{array}$ \\
Energy-block release movements (20 minutes) & $\begin{array}{l}\text { A sequence of } 12 \text { movements, including stretching, twisting, bending (forwards, backwards, and side- } \\
\text { ways), and squatting intended to increase circulation and "energy flow", performed slowly with joints } \\
\text { unlocked and slightly flexed and the limbs and torso relaxed. }\end{array}$ \\
Postures (20 minutes) & $\begin{array}{l}\text { Four postures were chosen: the crocodile pose, bridge pose, cobra pose, and sitting forward bend. All } \\
\text { postures are performed slowly with joints unlocked, with spinal wave and conscious intention. } \\
\text { Guided relaxation involved three parts: breathe and relax, visualize and affirm, and stretch and awaken. } \\
\text { Relaxation (10 minutes) }\end{array}$ \\
\hline
\end{tabular}

Table 2. Sample questions from IPPA questionnaire.

\begin{tabular}{lllllllllll}
\hline 1 During most of the day, my energy level is: & Very high & 1 & 2 & 3 & 4 & 5 & 6 & 7 & Very low \\
2 When there is a great deal of pressure being placed on me: & I remain calm & 1 & 2 & 3 & 4 & 5 & 6 & 7 & I get tense \\
3 As a whole, my life seems: & Dull & 1 & 2 & 3 & 4 & 5 & 6 & 7 & Vibrant \\
\hline
\end{tabular}


Table 3. Mean scores, Cronbach's $\alpha$, effect size $\eta^{2}$, f-ratios, and probability-level (of f-ratio) from two-way repeated measures ANOVA (interaction term), on Profile of Mood States Bipolar (POMS-Bi) and the Inventory of Positive Psychological Attitudes (IPPA) outcomes. $[\mathrm{SD}=$ standard deviation $]$.

\begin{tabular}{|c|c|c|c|c|c|c|c|c|c|c|c|c|}
\hline \multirow[t]{3}{*}{ Domains } & \multicolumn{4}{|c|}{ Yoga $(N=20)$} & \multicolumn{4}{|c|}{ Control (N=20) } & \multirow{3}{*}{$\begin{array}{c}\text { Cronbach's } \\
\alpha\end{array}$} & \multirow{3}{*}{$\begin{array}{c}\text { Effect } \\
\text { size } \eta^{2}\end{array}$} & \multirow{3}{*}{$\begin{array}{c}\text { F-ratio } \\
(\mathrm{df}=1.38)\end{array}$} & \multirow{3}{*}{$\begin{array}{c}\text { P-value } \\
\text { (yoga } \\
\text { versus } \\
\text { control) }\end{array}$} \\
\hline & \multicolumn{2}{|c|}{ Baseline } & \multicolumn{2}{|c|}{ End } & \multicolumn{2}{|c|}{ Baseline } & \multicolumn{2}{|c|}{ End } & & & & \\
\hline & Mean & SD & Mean & SD & Mean & SD & Mean & SD & & & & \\
\hline \multicolumn{13}{|l|}{ POMS-Bi } \\
\hline Composed-anxious & 2.35 & 0.54 & 3.25 & 0.36 & 2.38 & 0.52 & 2.78 & 0.61 & 0.87 & 0.19 & 8.88 & 0.005 \\
\hline Clear-minded-confused & 2.73 & 0.59 & 3.29 & 0.36 & 2.70 & 0.50 & 2.80 & 0.59 & 0.88 & 0.19 & 9.02 & 0.005 \\
\hline Elated-depressed & 2.55 & 0.53 & 3.20 & 0.33 & 2.57 & 0.52 & 2.75 & 0.56 & 0.87 & 0.16 & 7.41 & 0.010 \\
\hline Energized-tired & 2.05 & 0.49 & 2.89 & 0.52 & 2.20 & 0.61 & 2.42 & 0.65 & 0.88 & 0.22 & 10.8 & 0.002 \\
\hline Agreeable-hostile & 2.85 & 0.51 & 3.34 & 0.34 & 2.78 & 0.52 & 3.01 & 0.59 & 0.88 & 0.05 & 2.45 & 0.189 \\
\hline Confident-unsure & 2.37 & 0.60 & 3.02 & 0.54 & 2.38 & 0.43 & 2.59 & 0.54 & 0.87 & 0.16 & 7.34 & 0.010 \\
\hline \multicolumn{13}{|l|}{ IPPA } \\
\hline Life purpose satisfaction & 4.56 & 0.94 & 5.19 & 0.87 & 4.14 & 1.18 & 4.29 & 1.15 & 0.89 & 0.17 & 7.54 & 0.009 \\
\hline Self-confidence during stress & 3.63 & 0.94 & 4.51 & 0.75 & 3.82 & 1.34 & 3.66 & 1.09 & 0.90 & 0.25 & 12.8 & 0.001 \\
\hline
\end{tabular}

Table 4. Baseline characteristics of yoga and control group participants. [SD=standard deviation.]

\begin{tabular}{|c|c|c|c|c|}
\hline \multirow{2}{*}{$\begin{array}{l}\text { Demographic } \\
\text { information }\end{array}$} & \multirow{2}{*}{$\begin{array}{l}\text { Women } \\
(\mathrm{N})\end{array}$} & \multirow{2}{*}{$\begin{array}{l}\text { Men } \\
(\mathrm{N})\end{array}$} & \multicolumn{2}{|c|}{ Age } \\
\hline & & & Mean & SD \\
\hline Yoga group $(\mathrm{N}=20)$ & 17 & 3 & 40.6 & 11.40 \\
\hline Control group $(\mathrm{N}=20)$ & 19 & 1 & 38.0 & 9.58 \\
\hline
\end{tabular}

Table 5. Baseline health conditions

\begin{tabular}{lccc}
\hline Health condition & $\begin{array}{c}\text { Total } \\
\text { number of } \\
\text { participants } \\
\text { with this } \\
\text { health } \\
\text { condition }\end{array}$ & $\begin{array}{c}\text { Participants } \\
\text { in yoga } \\
\text { group with } \\
\text { this health } \\
\text { condition } \\
\text { (N) }\end{array}$ & $\begin{array}{c}\text { Participants } \\
\text { in control } \\
\text { group with } \\
\text { this health } \\
\text { condition } \\
\text { (N) }\end{array}$ \\
\hline Stress & 13 & 5 & 8 \\
Headaches & 11 & 4 & 7 \\
Weight problem & 11 & 4 & 7 \\
Lack of energy & 11 & 7 & 4 \\
Back problems & 10 & 6 & 4 \\
\hline
\end{tabular}

\section{Results}

\section{Baseline characteristics}

The baseline characteristics were very similar for the yoga intervention and the wait-list control groups (table 4). Of 48 participants in this study, 40 (83\%) completed both the baseline and end-of-program questionnaires.

Of the 40 participants, $36(90 \%)$ were women and the mean age of all participants was 39.3 years. At baseline, most participants in both the yoga and control groups had practiced yoga rarely or never [ 16 of 20 participants $(80 \%)$ in the yoga group and 17 of the 20 participants (85\%) in the control group]. The remainder of the participants all practiced yoga less frequently than once per week. Baseline scores (table 3) for the six domains of POMS-Bi did not differ significantly between the yoga and control groups [t-test: composed-anxious $(\mathrm{P}=0.96)$, clear-minded-confused $(\mathrm{P}=0.81)$, elated-depressed $(\mathrm{P}=0.97)$, energetic-tired $(\mathrm{P}=0.53)$, agreeable-hostile $(\mathrm{P}=0.66)$, confident-unsure $(\mathrm{P}=0.90)]$ or for the two domains of IPPA [life purpose and satisfaction $(\mathrm{P}=0.25)$ and self-confidence during stress $(\mathrm{P}=0.82)]$.

A summary analysis of the health information form showed that the five most common health challenges at baseline identified by the 40 participants were stress, headaches, weight problems, lack of energy, and back problems (table 5).

\section{Outcomes}

Participants in the yoga group attended an average of 1.15 classes per week (which reflects typical attendance at regular, weekly yoga classes offered to the general public). Participants who attended $<6$ classes were excluded from the analysis. Only 9 individuals (45\%) of the yoga group returned their home practice forms; consequently the degree of home practice was not included in our analyses.

In 7 of the 8 POMS-Bi and IPPA domains, scores for the yoga group improved 2-5 times more than those in the control group over the course of this study (table 3 ). The interaction term from a two-way ANOVA showed that in comparison with the control group, the yoga participants at the end of the program felt significantly less anxious, confused, depressed, tired, and unsure, and had a greater sense of life purpose and satisfaction 
and were more self-confident during stressful situations (table 3). Although the yoga group reported feeling more agreeable (less hostile) than the control group at the end of the program, this difference was not statistically significant (table 3 ).

\section{Discussion}

The results of this trial show that a six-week program of yoga had substantial positive effects on the emotional well-being and resilience to stress among a randomized group of adults employed at a British university. These results are generally consistent with the only other randomized (but not controlled) study published (24), which also found that yoga can be effective for improving well-being in the workplace.

In their study of 33 employees in a large Swedish company, Granath et al (24) used the PSS and Quality of Life Index (QOLI) and found that 10 weekly sessions of yoga resulted in significant reductions in perceived stress, stress behavior, and exhaustion (24). Although we used different assessment measures, both studies indicated the significant positive effects of yoga for the improvement of well-being and resilience to stress in the workplace.

Our results are also in accordance with other studies that have assessed the effectiveness of yoga for improving well-being and resilience to stress among a variety of populations. Lavey et al (49) found that even a single yoga class had a statistically significant effect on improving mood among 113 psychiatric inpatients. Patients were significantly less tense/anxious, less depressed/dejected, less angry/hostile, less confused/bewildered, and less fatigued after participating in a yoga class (49). In another study of a group of 24 emotionally distressed females, Michalsen et al (50) reported that participants who practiced yoga over 12 weeks were significantly less depressed/anxious and reported significantly more vigor than the control group who did not practice yoga (50).

Our results showed that only one of our POMS-Bi measures - anger/hostility - was non-significant (table 3). Granath et al (24) also found that yoga had a significant effect in reducing perceived stress, but not anger, in the workplace. Similarly, Michalsen et al (50) reported that yoga had a significant effect in reducing depression and anxiety, but not anger, in emotionally distressed women. Although it may be tempting therefore to draw conclusions regarding the inefficacy of yoga for reducing anger, Khalsa \& Cope (51) found the opposite - over an eight-week study evaluating performance anxiety among musicians, the increase in anger/hostility scores was significantly greater among the control than the yoga group
(51). Again, the limited data available do not permit a definitive conclusion to be drawn.

Our use of a randomized control design permitted an objective assessment of the effects of a short program of yoga on emotional well-being and resilience to stress. The lack of statistical differences in domain scores for the two groups at baseline illustrates the benefits of this approach - subsequent differences at the end of the program were therefore due to changes during the program and not initial conditions. The increase in scores for the yoga group during the six-week study period was substantially and significantly greater than that of the control group (table 3). This indicates clear support for our hypothesis that a short six-week programme of Dru Yoga can be effective for enhancing emotional well-being and resilience to stress in a workplace environment.

Although our study and that of Granath et al (24) found yoga to be effective for improving well-being in the workplace, these studies used different assessment tools, measured different populations, and used different forms of yoga. Therefore repeated trials using the same assessment tools and styles of yoga on multiple populations are needed before the effects of yoga can be generalized to the wider population.

Several factors limit the conclusions that can be drawn from our study. First, we placed no restrictions on the activities of the control group during the intervention period. Therefore the greater change in POMS-Bi and IPPA scores of the yoga group (table 3) could have been caused by participation in a new communal group and/or regular physical activity (ie, yoga), as well as the yoga treatment itself. Some authors have reported differences in response levels of active and passive controls for yoga intervention (37), as well as the effects of group-participation (52), however as these factors are confounded here we cannot assess their influence on our overall result. Similarly, we cannot exclude the possibility that the (unregulated) activities of the control group during the study period influenced their end-program scores. Control group scores did increase slightly over the course of the study (table 3), a result which may be due to general increases in emotional well-being and resilience to stress as the season moved from winter to spring (53).

Additional limitations include the use of a selfselected sample of university staff, the relatively modest number of participants $(\mathrm{N}=48)$ that included very few men, and the fact that we did not evaluate the long-term effects of yoga on well-being and resilience to stress.

Because participants in our study were self-selected, it can be assumed that they were a highly motivated group who wanted to practice yoga (54). Participant expectations may have included a desire to feel less stressed by the end of the six-week sessions (55) and this may have contributed to their perceived benefit (51). 
The size of the self-selected sample $(\mathrm{N}=48)$ was modest, although it compares favorably with other studies [eg, Lavey $(\mathrm{N}=113)$, Granath $(\mathrm{N}=33)$, Michelsen $(\mathrm{N}=24)$, and Khalsa \& Cope $(\mathrm{N}=15)]$. Furthermore, men were underrepresented in our study $-10 \%$ of the study participants in comparison to $42 \%$ of the staff employed at this university. Future studies should ensure that more men are represented in the sample.

We did not determine whether a single course of yoga intervention can be effective for long-term well-being and resilience to stress. Monthly follow-up sessions to monitor ongoing home practice could be implemented to measure the longer-term effects of yoga for improving well-being in the workplace (56). Future studies might also measure physiological indicators of stress such as heart rate, blood pressure, and salivary cortisol.

In summary, we have shown the positive effects of yoga in the workplace using a randomized controlled trial. As the evidence-base grows for the efficacy of yoga, recent research indicates that UK university employees are one population group in need of improved well-being and resilience to stress. Kinman \& Jones (12) reported that the demands placed on UK university staff have increased rapidly as a result of a substantial increase in student numbers, a decrease in external funding, and greater demands for accountability. Furthermore, there is evidence that the level of psychological well-being among university staff is low compared to other professions (13). Kinman \& Jones (12) recommended more training in developing resilience to stress for university staff. The results of our study indicate that yoga can be an effective tool for achieving this by helping employees attain greater positive health and well-being in the workplace.

\section{Acknowledgements}

The authors extend their gratitude to Dr Mansukh Patel and Chris Barrington for designing the Dru Yoga intervention and Padma McIntyre for teaching the classes.

\section{References}

1. Shuttleworth A. Managing workplace stress: how training can help. Ind Commer Train. 2004;36(2):61-5.

2. Sparks K, Faragher B, Cooper CL. Well-being and occupational health in the 21st century workplace. J Occup Organ Psychol. 2001;74(4):489-509.

3. Fuller G. HR fears for employee health as stress grips nation. Personnel Today [Internet]. 12 September 2006 [cited 31 March 2010]. Available from: www.personneltoday.com/ $\operatorname{articles} / 2006 / 09 / 12 / 37133 / \mathrm{hr}$-fears-for-employee-health-aswork-stress-grips-nation.html.

4. Health and Safety Executive (HSE). Work-related stress. London: HSE; 2008.

5. Confederation of British Industry (CBI). Workplace absence rises amid concerns over long-term sickness - CBI-AXA Survey [news release, Internet]. London: CBI; 2007 [cited 31 March 2010]. Available from: http://www.cbi.org. uk/ndbs/press.nsf/0363c1f07c6ca12a8025671c00381cc7/ 1032fea0526c09df802572b3003ea789? OpenDocument

6. Harter JK, Schmidt FL, Keyes CLM. Well-being in the workplace and its relationship to business outcomes: a review of the gallup studies. In: Keyes CLM, editor. Flourishing: the positive person and the good life. Washington DC: American Psychological Association; 2003.

7. Tugade M, Frederickson BL, Barrett LF. Psychological resilience and positive emotional granularity: examining the positive emotions on coping and health. J Pers. 2004;72(6):1160-90.

8. Waterman AS. Two conceptions of happiness: contrasts of personal expressiveness (eudairmonia) and hedonic enjoyment. J Pers Soc Psychol. 1993;64:678-91.

9. Seaward BL. Managing stress: principles and strategies for health and well-being. Boston (MA): Jones and Bartlett; 1994.

10. Horne JF, Orr JE. Assessing behaviors that create resilient organizations. Employ Relat Today. 1998;24:29-39.

11. Daniels K, Guppy A. Occupational stress, social support, job control, and psychological well-being. Hum Relat. 1994;47(12):1523-1544.

12. Kinman G. Pressure points. London: Association of University Teachers (AUT); 1998.

13. Kinman G, Jones F. Working to the limit. London: Association of University Teachers (AUT); 2004.

14. Tytherleigh M, Webb C, Cooper C, Ricketts C. Occupational stress in UK higher education institutions: a comparative study of all staff categories. Higher Educ Res Dev. 2005;24(1):41-61.

15. Iacovides A, Fountoulakis KN, Kaprinis S, Kaprinis G. The relationship between job stress, burnout, and clinical depression. J Affect Disord. 2003;75(3):209-21.

16. Dimsdale JE. Psychological stress and cardiovascular disease. J Am Coll Cardiol. 2008;51:1237-46.

17. Schneider S, Schmitt H, Zoller S, Schiltenwolf M. Workplace stress, lifestyle and social factors as correlates of back pain: a representative study of the German population. Int Arch Occup Environ Health. 2005;78(4):253-9.

18. Faragher EB, Cass M, Cooper CL. The relationship between job satisfaction and health: a meta-analysis. Occup Environ Med. 2005;62:105-12.

19. Fulwood A, Drossman DA. The relationship of psychiatric illness with gastrointestinal disease. Annu Rev Med. 1995;46:483-96.

20. National Institute for Health and Clinical Excellence (NICE). Workplace health promotion: how to encourage employees to be physically active. London: NICE; 2008. NICE Public Health Guidance 13. 
21. Kreis J, Bödeker W. Health-related and economic benefits of workplace health promotion and prevention - summary of the scientific evidence. Essen (Germany): BKK Bundesverband; 2004.

22. Caspersen CJ, Powell KE, Christensen GM. Physical activity, exercise and physical fitness: definitions and distinctions for health-related research. Public Health Rep. 1985;100:126-31.

23. Mohan G. Exploring yoga as therapy. Int J Yoga Ther. 2006;16:13-9.

24. Granath J, Ingvarsson S, Von Thiele U, Lundberg U. Stress management: a randomized study of cognitive behavioural therapy and yoga. Cogn Behav Ther. 2006;35(1):3-10.

25. Gura ST. Yoga for stress reduction and injury prevention at work. Work. 2002;19(1):3-7.

26. Heilbronn F. The use of hatha yoga as a strategy for coping with stress in management development. Manag Educ Dev. 1992;23(2):131-9.

27. Lane M. The tyranny of yoga [Internet]. BBC News; 2003 [cited 30 March 2010]. Available from: http://news.bbc. co.uk/1/hi/magazine/3174356.stm

28. Birdee G, Legedza A, Saper R, Bertisch S, Eisenberg D, Phillips R. Characteristics of yoga users: results of a national survey. J Gen Intern Med. 2008;23(10):1653-8.

29. Saper R, Eisenberg D, Davis R, Culpepper L, Phillips R. Prevalence and patterns of adult yoga use in the United States: results of a national survey. Altern Ther Health Med. 2004;10(2):20-1.

30. Barnes P, Bloom B. Complementary and alternative medicine use among adults and children. Natl Health Stat Rep. $2008 ; 12: 1-24$.

31. Doherty B. Company-sponsored yoga helps anxious workers breathe easier. San Francisco Business Times. 28 June 2002.

32. Gavin J, Mason R. The virtuous organization: the value of happiness in the workplace. Org Dyn. 2004;33(4):379-92.

33. International Association of Yoga Therapists (IAYT). Bibliograghies: yoga in the workplace [Internet]. Prescot (AZ): IAYT; 2004 [cited 30 March 2010]. Available from: http://www.iayt.org/site Vx2/publications/bibliographies.htm

34. Posadzki P, Parekh S. Yoga and physiotherapy: a speculative review and conceptual synthesis. Chin J Integr Med. 2009;15(1):66-72.

35. Dusek JA, Benson H. A model of the comparative clinical impact of the acute stress and relaxation responses. Minn Med. 2009;92(5):47-50.

36. Brisbon NM, Lowery GA. Mindfulness and levels of stress: a comparison of beginner and advanced Hatha yoga practitioners. J Relig Health. 2009 [Epub ahead of print].

37. Kiecolt-Glaser JK, Christian L, Preston H, Houts CR, Malarkey WB, Emery CF, et al. Stress, inflammation and yoga practice. Psychosom Med. 2010;72(2):113-21.

38. McDonald A, Burjan E, Martin S. Yoga for patients and carers in a palliative day care setting. Int J Palliat Nurs. 2006;12(11):519-23.

39. Barrington C, Goswami A, Jones A. Dru yoga: stillness in motion. Bangor (UK): Dru Publications; 2005.
40. Lorr M, McNair D, Heuchert J. Profile of mood states: bipolar supplement. North Tonawanda, New York: Multi-Health Systems, Inc; 2003.

41. Kass J, Friedman R, Leserman J, Caudhill M, Zuttermeister $\mathrm{P}$, Benson $\mathrm{H}$. An inventory of positive psychological attitudes with potential relevance to health outcomes: validation and preliminary testing. Behav Med. 1991;17(3):121-9.

42. Bejjani FJ, Snow B. Use of mood scores to assess athletic character in musicians. Med Probl Performing Artists. 1990;5(1): 45-8.

43. Sanders KA, Bruce NW. Psychosocial stress and treatment outcome following assisted reproductive technology. Hum Reprod. 1999;14(6):1656-62.

44. Chu J, Richdale AL. Sleep quality and psychological wellbeing in mothers of children with developmental disabilities. Res Dev Disabil. 2009;30:1512-22.

45. Laidlaw TM, Naito A, Dwivedi P, Hansi NK, Henderson DK, Gruzelier JH. The influence of $10 \mathrm{~min}$ of the Johrei healing method on laboratory stress. Complement Ther Med. 2006;14:127-32.

46. Quinn G, Keough M. Experimental design and data analysis for biologists. Cambridge (UK): Cambridge University Press; 2002.

47. Cohen J, Cohen P, West SG, Aiken LS. Applied multiple regression/correlation analysis for the behavioural sciences. Mawwah (NJ): Erlbaum; 2003.

48. Holm S. A simple sequentially rejective multiple test procedure. Scand J Stat. 1979;6:65-70.

49. Lavey R, Sherman T, Mueser K, Osborne D, Currier M, Wolfe R. The effects of yoga on mood in psychiatric inpatients. Psychiatr Rehabil J. 2005;28(4):399-402.

50. Michalsen A, Grossman P, Acil A, Langhorst J, Ludtke R, Esch $\mathrm{T}$, et al. Rapid stress reduction and anxiolysis among distressed women as a consequence of a three-month intensive yoga programme. Med Sci Mon. 2005;11(12):555-61.

51. Khalsa SB, Cope S. Effects of a yoga lifestyle intervention on performance-related characteristics of musicians: a preliminary study. Med Sci Mon. 2006;12(8):325-31.

52. Javnbakht M, Hejazi Kenan R, Ghasemi, M. Effects of yoga on depression and anxiety of women. Complement Ther Clin Pract. 2009;15(2):102-4.

53. Eagles JM. Seasonal affective disorder. Br J Psychiatr. 2003;182:174-6.

54. Oken BS, Zajdel D, Kishiyama S, Flegal K, Dehen C, Haas $\mathrm{M}$, et al. Randomized, controlled, six-month trial of yoga in healthy seniors: effects on cognition and quality of life. Altern Ther Health Med. 2006;12(1):40-7.

55. Smith C, Hancock H, Blake-Mortimer J, Eckert K. A randomized comparative trial of yoga and relaxation to reduce stress and anxiety. Compl Ther Med. 2007;15(2):77-83.

56. Garfinkel M, Singhal A, Katz W, Allan D, Resheter R, Schumacher HR. Yoga-based intervention for carpel tunnel syndrome: a randomised trial. JAMA.1998;280:1601-3.

Received for publication: 6 October 2009 